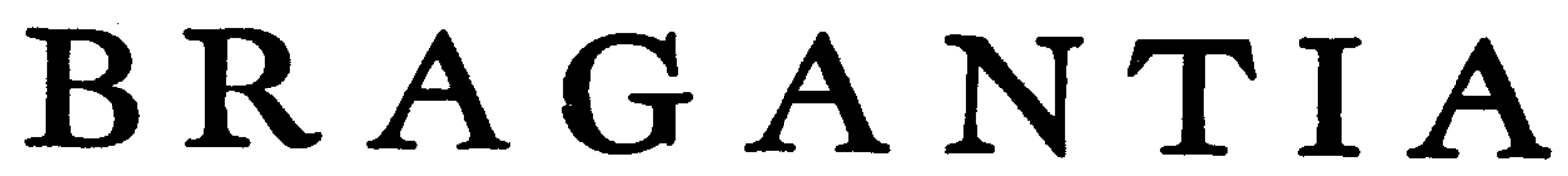

Boletim Técnico da Divisão de Experimentação e Pesquisas I N S T I T UTO A GRONÔM I CO

\begin{tabular}{lll}
\hline Vol. 2 & Campinas, Janeiro de 1942 & N. $^{\circ} 1$ \\
\hline \hline
\end{tabular}

\title{
NOTAS SOBRE FLORESCIMENTO E FRUTIFICAÇÃO DA MANDIOCA
}

E. A. Graner (*)

Propagada sempre por meio vegetativo, pouco se sabe até agora a respeito do florescimento e da frutificação da mandioca. Planta cultivada para exploração de suas raizes e com ótimo pegamento por meio de estaquia, processo muito vantajoso por estabelecer clones, pode parecer, à primeira vista, de somenos importância conhecer minúcias sobre o seu florescimento. Desde, porem, que se tenha em vista o melhoramento da planta, tais minúcias se tornam de grande valor, pois novas formas poderão ser obtidas, principalmente por meio de cruzamentos entre as variedades cultivadas. Cruzamentos com novas formas poliplóides agora obtidas experimentalmente por meio da colchicina (2) são tambem de grande interesse, bem como cruzamentos com as diferentes espécies do gênero, os quais desempenharão, possivelmente, grande papel no conhecimento da filogenia desta planta de tão grande valor econômico.

As observações feitas se referem principalmente à variedade "Vassourinha Paulista", com a qual estamos trabalhando mais intensivamente.

Agradecemos ao dr. Oscar Monte, entomologista do Instituto Biológico, todas as determinações do nosso material entomológico, e ao prof. Carlos T. Mendes, diretor da Fazenda Modelo da Escola "Luiz de Queiroz", a permissão para realizarmos observações nas culturas de mandioca da referida Fazenda.

A mandioca floresce regularmente, com início aos 6 meses, e este fato passa quase sempre despercebido pelos motivos explicados acima.

(") Da Escola Superior de Agricultura "Luiz de Queiroz", Universidade de São Paulo 
Em cada ramificação da planta aparece sempre uma inflorescência, sendo que os frutos da inflorescência da primeira ramificação, no geral, não se desenvolvem. Oेs frutos mais frequentemente encontrados são os que se desenvolvem nas ramificações seguintes.

Os dois sexos se encontram separados em diferentes flores, numa mesma planta. A morfologia dessas flores foi já por nós descrita (1) e pode ser resumida como segue: flor imperfeita, apétala; a flor masculina medindo, no comprimento, aproximadamente dois terços da flor feminina, que é de cerca de $15 \mathrm{~mm}$. Cálice em forma campanulada. Flor masculina com pedicelo delgado, curto e cálice 5- fendido até a parte mediana. Internamente um disco com 10 dentes e no centro do disco um rudimento de ovário. Do espaço entre os dentes saem os filetes das anteras, em número de 10, dos quais, 5 são longos e 5 são curtos. Flor feminina com pedicelo delgado, porem maior que o da flor masculina, apresentando-se sempre recurvado. Cálice 5-fendido até a sua base e, internamente, um disco arredondado, tendo na parte central um ovário muito desenvolvido. Ovário de 3 carpelos, possuindo externamente 6 ângulos alados e muito enrugados. Estigma sessil, carnoso, franjado e viscoso, muito desenvolvido, cerca de dois terços de ovário. Ovário de 3 lojas, em cada uma das quais se desenvolve normalmente uma semente.

A coloração das flores na variedade Vassourinha Paulista é amarelada. Sabemos, porem, que esta variedade é heterozigota para muitos caracteres, esperando-se, porisso, quanto à coloração da flor, tambem uma segregação quando plantada de sementes.

O número de flores femininas em cada inflorescência é muito pequeno - em regra 6 por inflorescência. $O$ número de flores masculinas é já bem maior, podendo ser avaliado, grosseiramente, em umas 50 por inflorescência. Para cada flor feminina correspondem assim, de uma maneira geral, 10 flores masculinas. De acordo com estudos histológicos anteriores (1), pode-se avaliar a quantidade de polen que cada flor masculina produz. Verificamos que em cada loja da antera se desen. volve um arquespório de uma só camada de células. Calculando como sendo 10 o número dessas células e cada uma, após a meiose, produzindo 4 grãos de polen que são muito grandes, teremos 40 grãos de polen por loja e 160 por antera. Como são 10 anteras, teremos, então, 1600 grãos de polen para cada flor. Verificamos tambem que $50 \%$ dos grãos de polen não parecem normais; são menores e não se colorem bem. Supondo, portanto, que $50 \%$ de polen sejam inviaveis, teríamos ainda cerca de 800 grãos de polen para cada flor masculina e cerca de 8000 para cada flor feminina, o que parece suficiente para garantir a polinização por insetos, em condições normais.

O número de sementes que uma planta pode produzir normalmente é muito pequeno. Considerando como ótima a ramificação da mandioca 3 vezes, teríamos 13 inflorescências, cada uma com 6 flores femininas, dando um total de 78 flores femininas; desenvolvendo-se 3 sementes 
em cada uma destas flores, teríamos 234 sementes por planta, no máximo, e em condições muito satisfatórias. Esse número, porem, está muito longe de ser atingido, por motivos que veremos adiante.

Em mandioca, verifica-se uma protoginia bastante acentuada. Conforme se pode verificar pela figura 1 , as flores femininas abrem-se muito antes que as flores masculinas, da mesma ramificação. Quando as flores masculinas se encontram na ocasião de abrir, as flores femininas já não teem mais estigma, como se pode ver na parte inferior da mesma figura 1 . Parece que podemos assim explicar a razão por que os frutos da inflorescência formada na primeira ramificação não se desenvolvem no geral : falta de polen. Não se dando, por motivos fisiológicos, o desenvolvimento, ao mesmo tempo, das demais inflorescências, em número bem maior, esse fato determina um desencontro, de forma a haver polen em umas quando se dá a abertura das flores de outras, o que favorece tambem uma autofecundação.

Feitas as observações acima, passemos agora a examinar o estrago causado pelas larvas de duas moscas que prejudicam muito a fertilização e a frutificação, de maneira a não permitir, muitas vezes, o desenvolvimento de um fruto sequer.

As flores masculinas são extremamente atacadas pela larva da mosca Teleocoma crassipes Aldrich (fig. 2). A intensidade do ataque pode variar bastante, de acordo com a época. Em um pequeno lote, plantado em canteiros para trabalhos de cruzamentos e que floresceu no mês de abril, dificilmente se encontrava uma flor masculina que não tivesse a larva dentro, a qual, alimentando-se do polen, estraga completamente a flor, que nem chega a abrir. Pode-se avaliar assim a intensidade do ataque e as dificuldades que disso resultam para os trabalhos de melhoramento. A larva, que mede cerca de $3 \mathrm{~mm}$ de comprimento, é branca, podendo aparecer amarelada em vista do polen que come. Flores masculinas foram trazidas para o laboratório e colocadas em pequenos vidros, com areia úmida no fundo; após 6 dias nelas apareceram as moscas, que foram conservadas para classificação.

Essa mosca, segundo Carlos Moreira (5) e observações de Dario Mendes (3) atacam os brotos novos impedindo, porisso, o próprio florescimento. Encontramos tambem muitos brotos novos atacados, mas pelas moscas I.onchaea pendula Bezzi e Atherigona excisa Thom. Estes estragos dos brotos novos são muito conhecidos nas plantações de mandioca e fazem com que a planta brote muito irregularmente, reagindo assim aos danos produzidos pelas larvas. Conforme a intensidade do ataque, a frutificação pode ficar extremamente prejudicada. Fazendo observação em uma plantação maior, na Fazenda Modelo da Escola Superior de Agricultura "Luiz de Queiroz", e num lote bastante atacado, não pudemos encontrar mais do que 5 frutos em uma planta, sendo muito comuns plantas sem nenhum ou com apenas um ou dois frutos. Se o ataque é menos intenso, como verificamos em outro lote da mesma Fazenda, plantado em lugar muito distante do primeiro, podem-se encontrar muitas flores masculinas abertas ao lado de botões atacados pela larva. 
Neste lote a frutificação foi melhor, podendo-se avaliar como sendo 10 o número de frutos por planta, o que é ainda muito pouco.

$O$ estrago causado por essa mosca se reflete grandemente no número de sementes produzidas. Quando o ataque é muito forte, encontram-se sempre frutos com um bvulo apenas em desenvolvimento, as outras duas lojas ficando vazias, provavelmente por falta de polinização. Do campo onde o ataque se mostrava mais intenso, colhemos diversos frutos que, cortados ao meio, apresentaram os resultados contidos no quadro a seguir, quanto ao número de b́vulos em desenvolvimento:

\begin{tabular}{c|c|c}
\hline $\begin{array}{c}\text { Sementes em } \\
\text { desenvolvimento } \\
\text { nas lojas }\end{array}$ & $\begin{array}{c}\text { Número } \\
\text { de } \\
\text { frutos }\end{array}$ & $\%$ de frutos \\
\hline 1 & 76 & 46,3 \\
2 & 61 & 37,2 \\
3 & 27 & 16,5 \\
\hline
\end{tabular}

Dos 164 frutos colhidos, deveríamos obter 492 sementes, mas, no entanto, somente 279 estavam em desenvolvimento, ou sejam 56,7\%.

No lote onde $o$ ataque era menor, constatamos o resultado seguinte :

\begin{tabular}{c|c|c}
\hline $\begin{array}{c}\text { Sementes em } \\
\text { desenvolvimento } \\
\text { nas lojas }\end{array}$ & $\begin{array}{c}\text { Número } \\
\text { de } \\
\text { frutos }\end{array}$ & $\%$ de frutos \\
\hline 1 & 129 & 32,1 \\
2 & 166 & 41,5 \\
3 & 107 & 26,6 \\
\hline
\end{tabular}

Verificamos aquí uma melhoria quanto ao número de sementes produzidas. Dos 402 frutos colhidos deveríamos obter 1206 sementes, mas somente 783 sementes estavam em desenvolvimento, ou sejam $64,9 \%$. Em 150 frutos colhidos no mesmo campo, mais tarde, quando já secos, encontramos 285 sementes, em vez das 450 que deveriam ter sido produzidas normalmente, ou sejam $63,3 \%$.

Observações feitas num lote da variedade Vassourinha Grande, onde o ataque não havia sido tambem muito forte, apresentaram o resultado seguinte: 


\begin{tabular}{c|c|c}
\hline $\begin{array}{c}\text { Sementes em } \\
\text { desenvolvimento } \\
\text { nas lojas }\end{array}$ & $\begin{array}{c}\text { Número } \\
\text { de } \\
\text { frutos }\end{array}$ & $\%$ de frutos \\
\hline 1 & 4 & 6,2 \\
3 & 16 & 23,5 \\
3 & 48 & 70,3 \\
\hline
\end{tabular}

Nos 68 frutos, que deveriam produzir 204 sementes, estavam em desenvolvimento 170 sementes, ou sejam 83,3\%.

As observações realizadas parecem indicar que a produção de sementes está diretamente ligada ao maior ou menor ataque das flores masculinas pela larva da mosca Teleocoma crassipes Aldrich.

Alem dos estragos produzidos por essa larvazinha, teremos que contar ainda com os estragos que serão produzidos, após a fecundação e durante o desenvolvimento do fruto, pela larva de uma outra mosca, de nome Anastrepha pickeli C. Lima (fig. 3). A larva desta mosca, que mede cerca de $10 \mathrm{~mm}$, é de cor branca amarelada e penetra no fruto quando ainda novo, ficando deste orifício apenas um sinal, como se vê na figura 4. Uma vez dentro do fruto, a larva o estraga completamente, impedindo a formação das sementes, conforme se vê na mesma figura 4 . O estrago produzido por esta larva é tambem bastante notavel, conforme se deduz dos resultados seguintes:

\begin{tabular}{c|c|c|c|c}
\hline \hline Campo & $\begin{array}{c}\text { Frutos } \\
\text { atacados }\end{array}$ & $\begin{array}{c}\text { Frutos } \\
\text { não } \\
\text { atacados }\end{array}$ & Total & \% de frutos atacados \\
\hline A & 67 & 164 & 231 & 29,0 \\
B & 24 & 402 & 426 & 5,6 \\
C & 34 & 68 & 102 & 33,3 \\
\hline \hline
\end{tabular}

Campo $A=$ onde o ataque pela larva na flor masculina foi muito intenso; Campo $\mathrm{B}=$ onde o mesmo ataque foi muito menor;

Campo $C=$ da variedade "Vassourinha Grande", onde o ataque pela mesma larva foi tambem pequeno.

Segundo os dados acima, não há correlação entre os ataques produzidos pelas larvas das duas moscas.

Os frutos, quando atacados, ficam amarelecidos, permitindo assim facil reconhecimento em confronto com os não atacados. Frutos ata- 
cados, trazidos para o laboratório, foram conservados em vidros, com areia úmida e, após cerca de 20 dias, sairam as primeiras moscas, que foram tambem conservadas para a classificação. Em alguns casos saiu do fruto não a mosca Anastrepha pickeli C. Lima, mas, sim, um seu parasita, Opius sp. Outras espécies do mesmo gênero Anastrepha e produzindo os mesmos estragos em mandioca são tambem conhecidas.

Afora as duas larvas que prejudicam muito o florescimento e a frutificação, encontramos tambem, nas hastes de mandioca, alem de outro material ainda não determinado: Lonchaea fendula Bezzi, Araecerus fasciculatus De Geer, Eulechriops manihoti Monte.

Verificamos, então, o motivo por que existe uma baixa percentagem de frutificação na mandioca. Essa falta de frutos em mandioca foi já observada no século XVII por Piso, segundo Pickel (6).

Os trabalhos de cruzamento com a planta tornam-se extremamente dificultados, principalmente pelo ataque da larva da mosca Teleocoma crassipes Aldrich na flor masculina, o que impede o florescimento normal, não se encontrando, muitas vezes, uma única flor masculina em condições de fornecer o polen necessário. Para sanar este inconveniente seriam necessárias muitas plantas para garantir um mínimo de polen, o que nem sempre é viavel, por falta de espaço.

A mosca dos frutos já não apresenta grandes dificuldades para o trabalho, uma vez que o seu ataque pode ser evitado. $O$ ataque da flor masculina pode, porem, tornar-se um fator decisivo na polinização.

O cruzamento é muito facil de ser efetuado, já por ter a planta os sexos em flores separadas, já por serem as flores bastante grandes. Um pequeno saco de pano bem fino, medindo $5 \times 8 \mathrm{~cm}$, é suficiente para proteger 2 flores femininas, cortando-se a ramificação das flores masculinas. Pela transparência, pode-se verificar quando as flores femininas se abrem e o trabalho consiste, então, em procurar as flores masculinas um pouco antes de se abrirem. Estas teem já polen suficiente para a polinização. $O$ saquinho deve, depois da polinização, continuar cobrindo as flores femininas e aí permanecer para evitar o ataque pela mosca do fruto.

Antes que um método prático possa ser aplicado no combate à mosca da flor, os trabalhos experimentais teem que ficar grandemente dificultados. Torna-se, por isso, aconselhavel realizar os cruzamentos, a-fim-de se fazer as combinações desejadas e, obtidas algumas sementes, estabelecer clones desses cruzamentos e com eles realizar plantações de muitos indivíduos, cada clone bem separado do outro, deixando-se depois que a polinização e frutificação se processem naturalmente, para se aproveitar, finalmente, uma percentagem de sementes destinadas aos estudos da geração seguinte. Este processo, que, por enquanto, parece o único viavel, é tambem muito demorado. Muitas vezes o indivíduo obtido de uma semente cruzada não oferece estacas suficientes para a plantação de muitas plantas. Precisa-se, então, de mais um novo ciclo 
vegetativo da planta, o que corresponde a dois anos somente para a obtenção de estacas suficientes para a plantação de muitos indivíduos, os quais só depois de mais um ano, ou seja no total 3 anos, fornecerão sementes para a geração $F^{2}$. Alem disso, torna-se necessário averiguar até que ponto este processo pode ser utilizado, pois não se sabe ainda a que distância cada clone precisa ser separado do outro, a-fim-de não permitir cruzamentos entre eles. A-pesar dos inconvenientes, parece ainda ser o processo mais prático para a obtenção de um grande número de sementes.

Infelizmente, a mandioca é, em extremo, sensivel à redução de luz, e isto impede que as plantas possam ser cultivadas em estufas. A figura 6 mostra uma das plantas de 6 meses, que deixamos crescer na estufa. A planta cresce sempre, sem ramificar-se, ficando os internódios muito mais alongados do que nas plantas que se desenvolvem fora da estufa. A planta não floresce, não se ramificando portanto. Depois dos 6 meses fizemos uma poda na altura aproximadamente de 2 metros, e a brotação que veio continuou o desenvolvimento de maneira idêntica ao do broto anterior. Alcançada a altura da estufa, este broto continuou a crescer acompanhando o teto, tambern sem nenhuma ramificação. Uma nova poda foi efetuada e a reação foi idêntica. Pensamos então em cultivar as plantas em vasos, fora da estufa, para, no momento do florescimento, transportá-los para ela, mas, como se verifica pela figura 5, as plantas não se desenvolveram, estando já com 12 meses nos vasos.

Achamos, porisso, que a polinização da mandioca em estufas não é possivel e que ela terá que ser efetuada em condições naturais. Se um método prático de controle da mosca da flor não for encontrado, o único processo para obtenção de um grande número de sementes, para estudos principalmente de $F^{2}$, será aquele descrito aquí, tornando-se necessário saber com que segurança pode ele ser utilizado, por meio de um estudo mais circunstanciado da biologia da flor e o que não é tambem muito facil de ser realizado, em virtude das complicações mencionadas.

\section{SUMMARY}

The flowering habits and the fructification of cassava M. utilissima Pohl were described. Attention was called to the small production of flowers per plant and to the attack of male flowers by the fly Teleocoma crassipes Aldrich and of the fruit by the fly Anastrepha pickeli C. Lima.

The difficulties of controlled pollination were emphasized and a practical method of obtaining $F^{2}$ seeds were discussed.

\section{LITERATURA CITADA}

1. Graner, E. A. Contribuição para o estudo citológico da mandioca. Publicação da Escola Superior de Agricultura "Luiz de Queiroz", pgs 1-28, 67 figs, 1935.

2. Graner, E. A. Polyploid cassava induced by colchicine treatment. Journal of Heredity 32: 281-288. Fig. 18-24. 1941.

3. Lima, A. Costa Em Terceiro catálogo dos insetos que vivem nas plantas do Brasil. Ministério da Agricultura, Rio-de-Janeiro, pg. 1-460.1936. 
4. Mondes, C. T. Contribuição para o estudo da mandíoca. Publicação da Secr. Agr. Ind. Com. do Est. S. Paulo, pg. 1-99, 1940.

5. Moreira. C. Em Entomologia Agrícola Brasileira. 2." edição, pg. 1.274. Ministério da Agricultura, Rio-de-Janeiro, 1939.

6. Pickel, D. B. Cultura e Indústria da mandioca no século XVII segundo Piso. Revista de Agricultura 13:99-106. 1938.

\section{EXPLICACAO DAS FIGURAS}

Fig. 1 - Flores masculinas e femininas de mandioca, mostrando uma protoginia muito acentuada. Na parte superior da figura, flores femininas no momento da polinização enquanto que as flores masculinas da mesma ramificação ainda se encontram na forma de botão. Na parte de baixo, flores masculinas no momento de se abrirem e flores femininas da mesma ramificação, já sem. estigma ( $x$ 1).

Fig. 2 - A larva que prejudica a flor masculina e a respectiva mosca Teleocoma cras. sipes Aldrich (x 10).

Fig. 3 - Larva que prejudica o fruto a a respectiva mosca Anastrepha pickeli C. Lima ( 6 ).

Fig. 4 - Frutos atacados pela larva da mosca Anastrepha pickeli C. Lima (x 2).

Fig. 5 - Plantas de um ano, conservadas fora da estufa, em vasos, para serem para ela levadas na ocasião do florescimento. As plantas não suportam este tratamento.

Fig. 6 - Planta com 6 meses, mostrando o desenvolvimento na estufa. Estas plantas. crescem continuamente sem ramificar-se e sem florescer. Ao lado, raizes de duas dessas plantas, mostrando que a alteração ao crescimento e florescimento e não quanto à produção. 


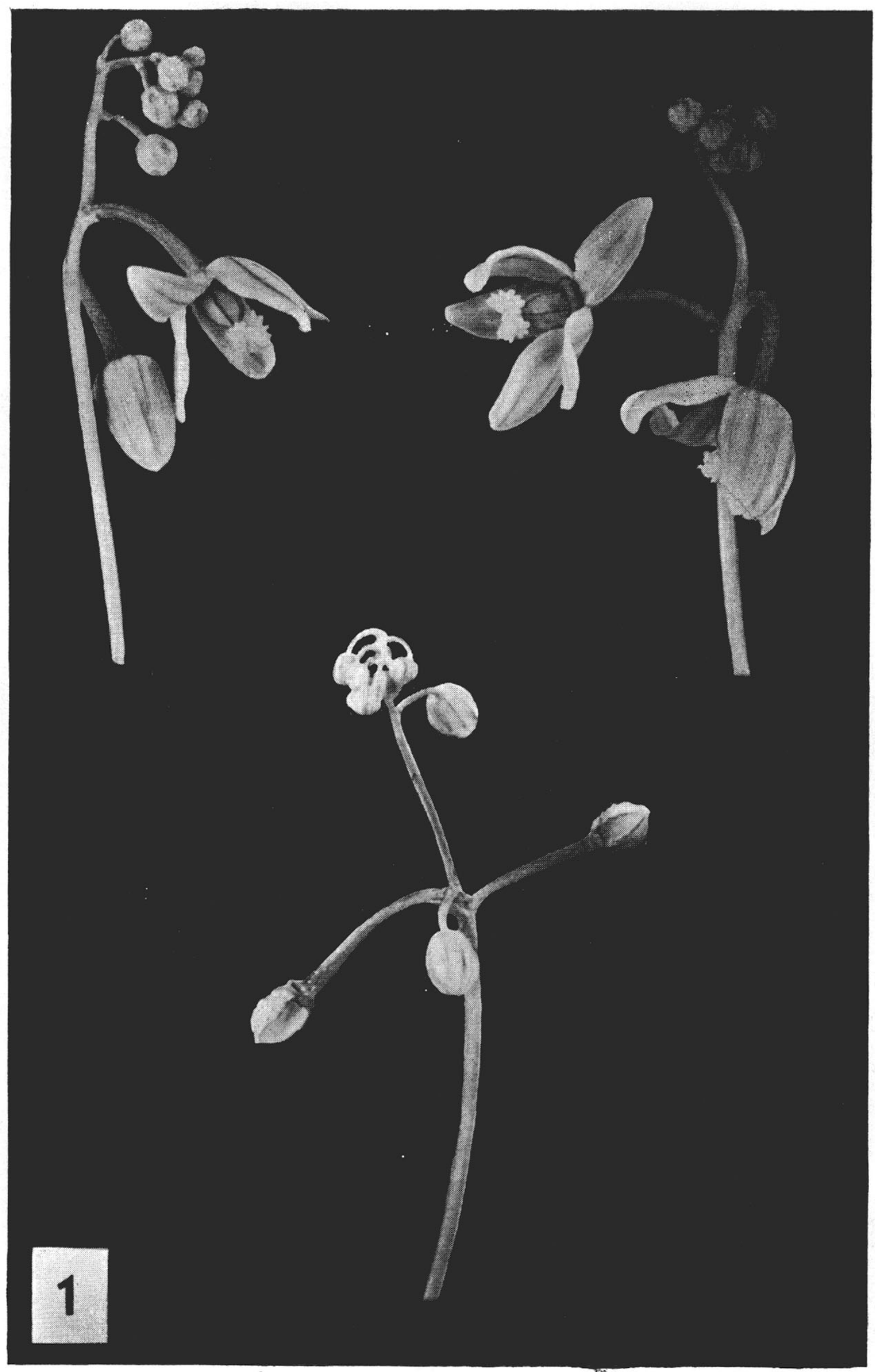



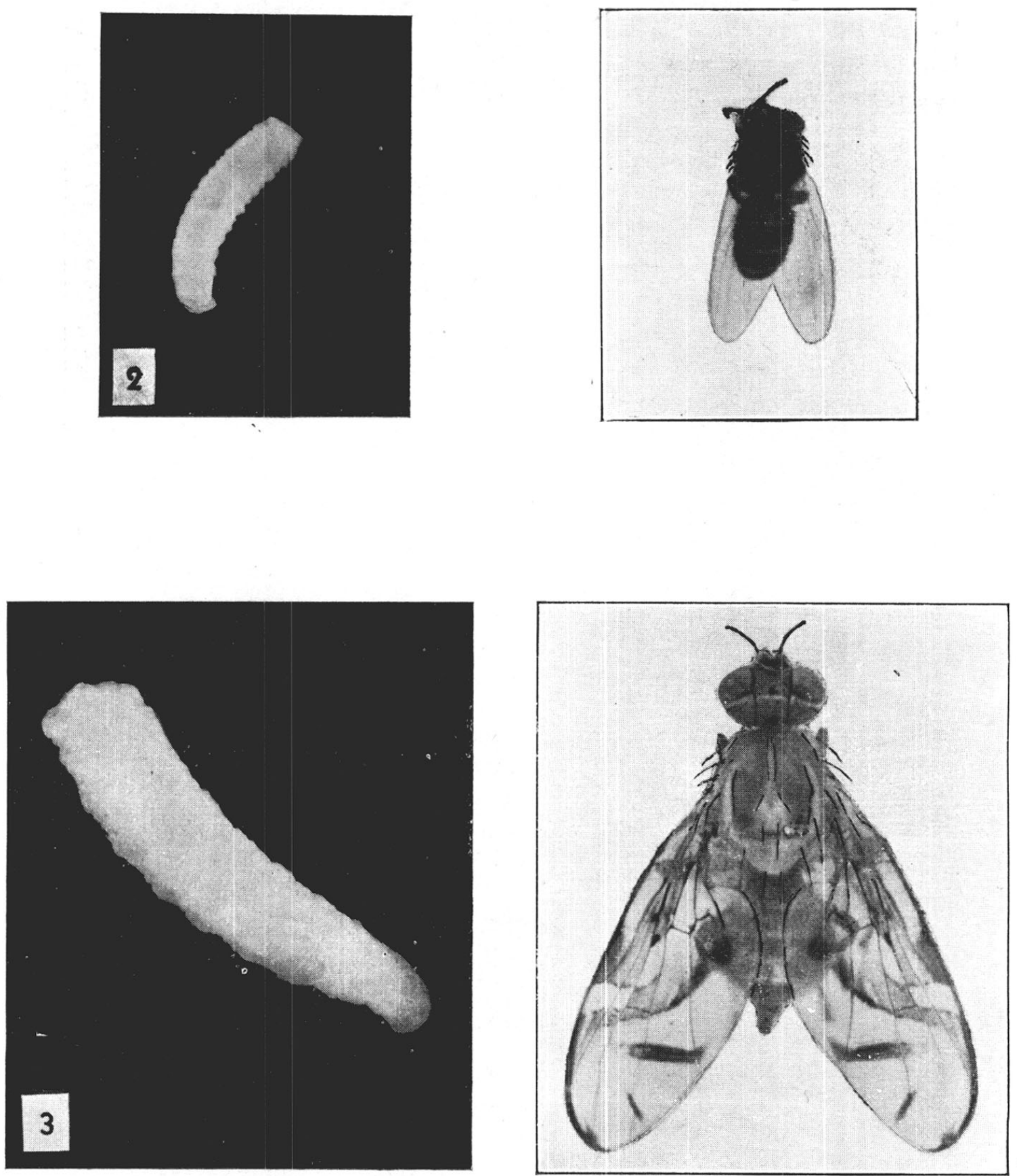

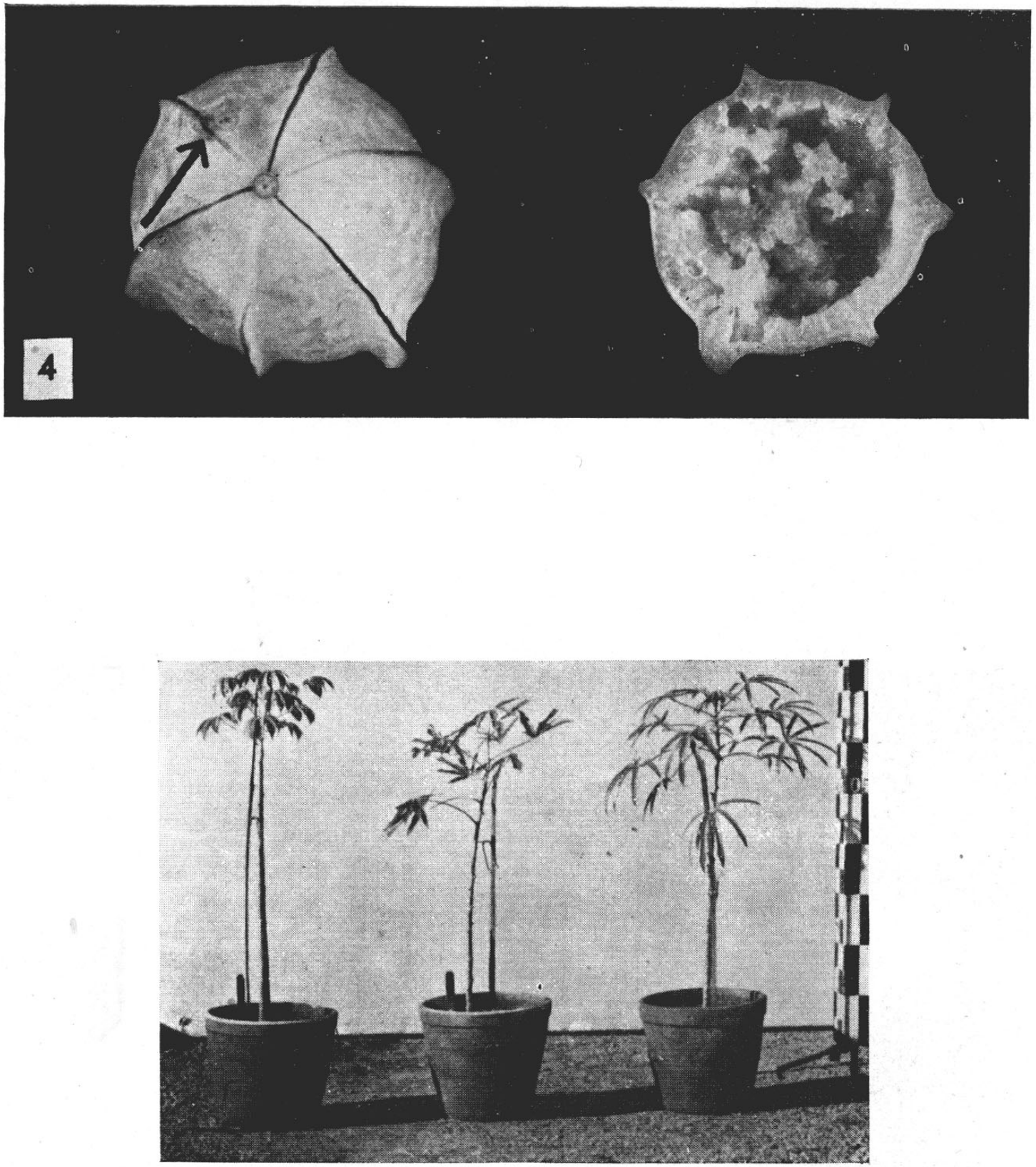

5 


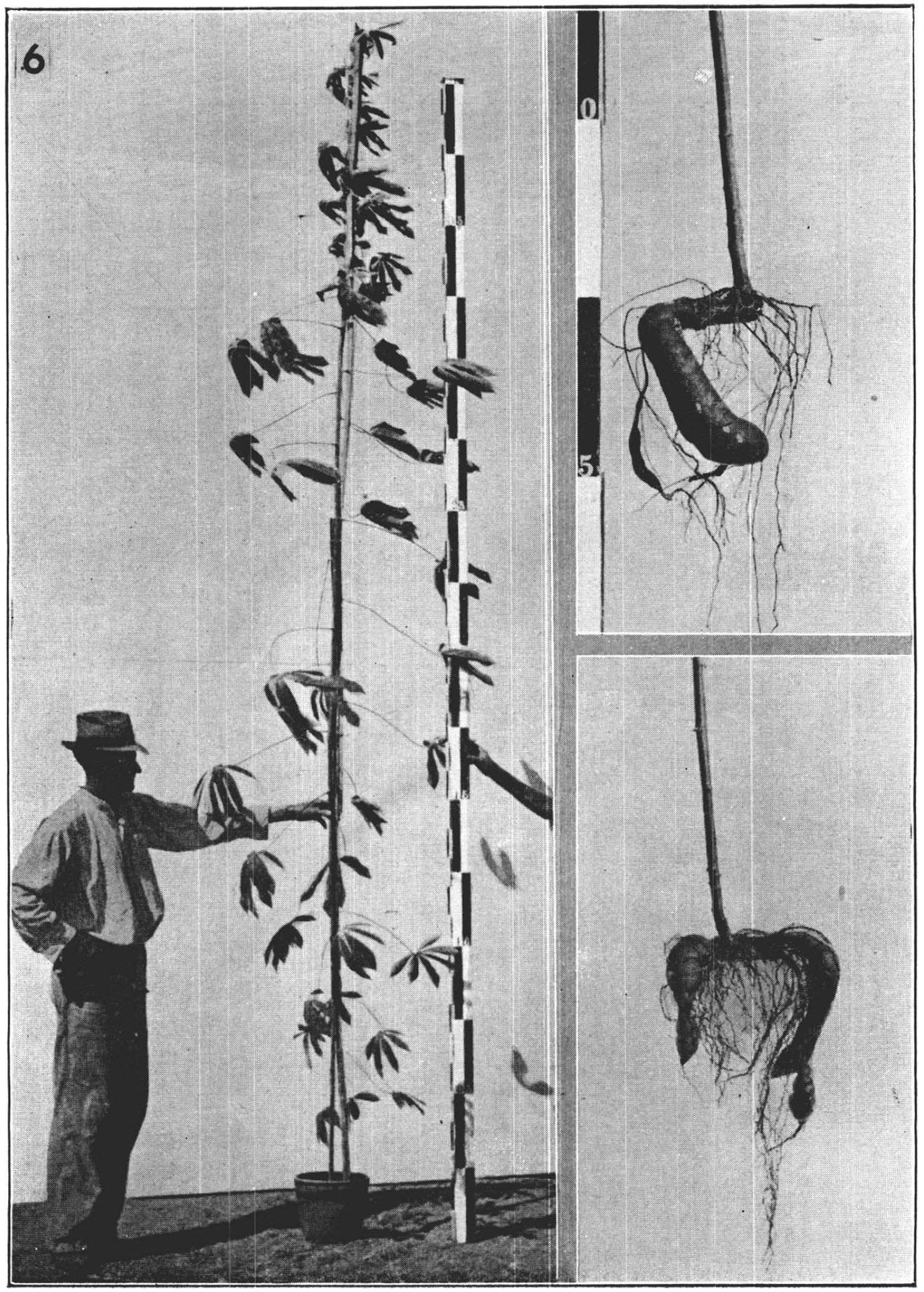

